\title{
A Large Radicular Cyst Involving the Maxillary Sinus - A Case Report
} M. Bala Jagadish ${ }^{1 *}$, Dr. Sridhar Reddy Kanubaddy ${ }^{2}$

${ }^{1}$ Post Graduate MDS Oral and Maxillofacial Surgery, Narayana Dental College, Andhra Pradesh, India

${ }^{2}$ Associate Professor, Department of Oral and Maxillofacial Surgery, Narayana Dental College, Andhra Pradesh, India

DOI: $10.36347 /$ sjds.2021.v08i04.003

| Received: 12.03.2021 | Accepted: 25.04.2021 | Published: 30.04.2021

*Corresponding author: M. Bala Jagadish

Abstract

Radicular cysts are slow growing and are the most common odontogenic cystic lesions of inflammatory origin affecting the jaws. Most radicular cysts are small, but they can reach a large size. Sometimes, the cyst may cause displacement of surrounding structures. The purpose of this article is to report the case of a large radicular cyst that had displaced the floor of the maxillary sinus and treated by enucleation along with apicectomy and antrostomy.

Keywords: Radicular Cyst Involving, antrostomy, Maxillary Sinus.

Copyright ( 12021 The Author(s): This is an open-access article distributed under the terms of the Creative Commons Attribution 4.0 International License (CC BY-NC 4.0) which permits unrestricted use, distribution, and reproduction in any medium for non-commercial use provided the original author and source are credited.

\section{INTRODUCTION}

Radicular cysts are the most common cystic lesions of the jaws comprising of about $52.3 \%$ jaw cysts and $62 \%$ of odontogenic cysts [1]. They develop from cystic degeneration of cells rests of malassez secondary to the inflammatory stimulation arising from necrotic pulp. Caries and traumatic injuries to the primary teeth and permanent teeth are the most frequent aetiological factors. The normal treatment radicular cysts include total enucleation in the case of small lesions, marsupilization for decompression of large cysts or combination of both.

This is a case report of a large radicular cyst occupying entire maxillary sinus treated by enucleation along with anstrostomy.

\section{CASE REORT}

A 23 year old male patient presented to the department of Oral and Maxillofacial Surgery, Narayana Dental College and Hospital with a chief complaint of painless swelling on left side of face since 6 months.

Patient gives a positive history of trauma in maxillary anterior region ten years back. The patient noticed mild swelling in the left side of the face since 6 months associated with halitosis and post nasal drip. On extra oral examination a well-defined non tender hard bony swelling was noted over the left maxillary region.
Intra oral examination revealed non vital, fractured left maxillary central incisor with cortical perforations noted in relation to first premolar and in palatal aspect in relation to canine and first premolar. Aspiration revealed a straw coloured fluid. Orthopantomogram revealed a unilateral radiolucency lesion in the left maxilla above the apices of the 22, 23, and 24,25,26,27 with no root resorption. The coronal section of CT revealed widening of left maxillary sinus with homogeneous opacification extending to the palate region and deviation of nasal septum is seen. Based on clinical and radiographic examination a provisional diagnosis of radicular cyst was made andincisional biopsy was performed which was suggestive of odontogenic cyst.

\section{SURGICAL PROCEDURE}

Surgical enucleation was performed under general anaesthesia. Crevicular incision was made from 11 to 26 and mucoperiosteal flap was elevated. Using bone nibbler surgical window was created over the thinned out cortical bone and cystic lining was removed in toto. Copious irrigation of the cystic cavity was performed using betadine and saline. Apicectomy was done for 21 and 22 .The cystic cavity was packed with betadine soaked gauze, lateral nasal antrostomy was performed and the gauge pack was pulled out through the antrostomy side onto the nose. The oral wound is closed using 3-0vicryl and hemostasis was achieved. 


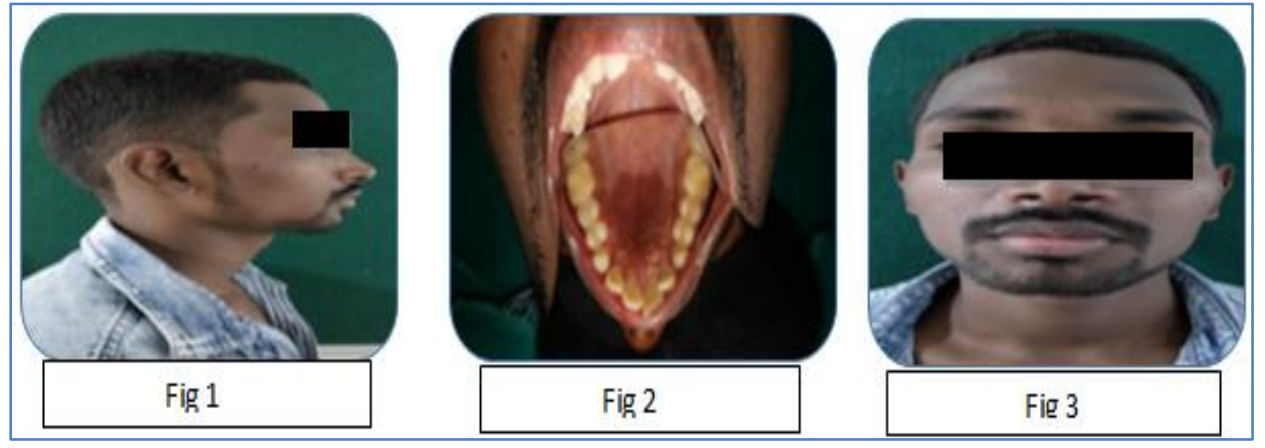

Fig-1-3 Preoperative photographs

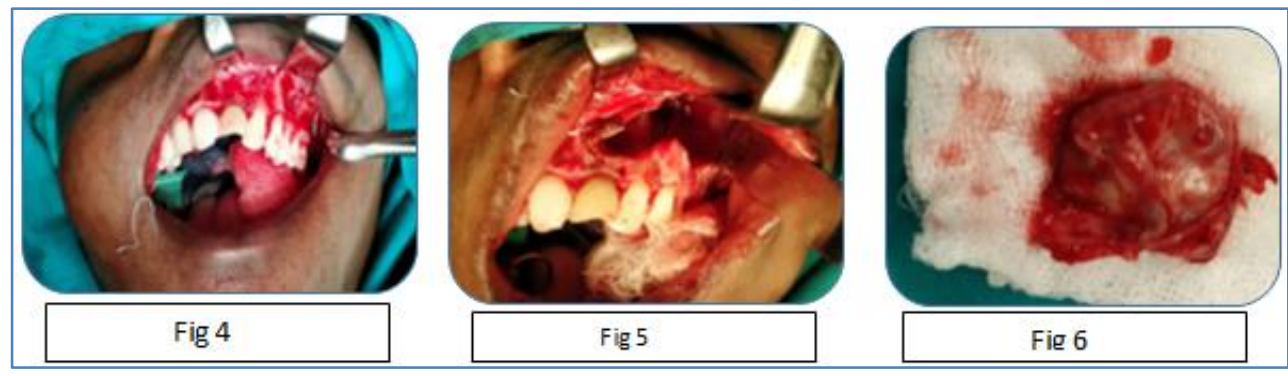

Fig-4-6: Intraoperative photographs

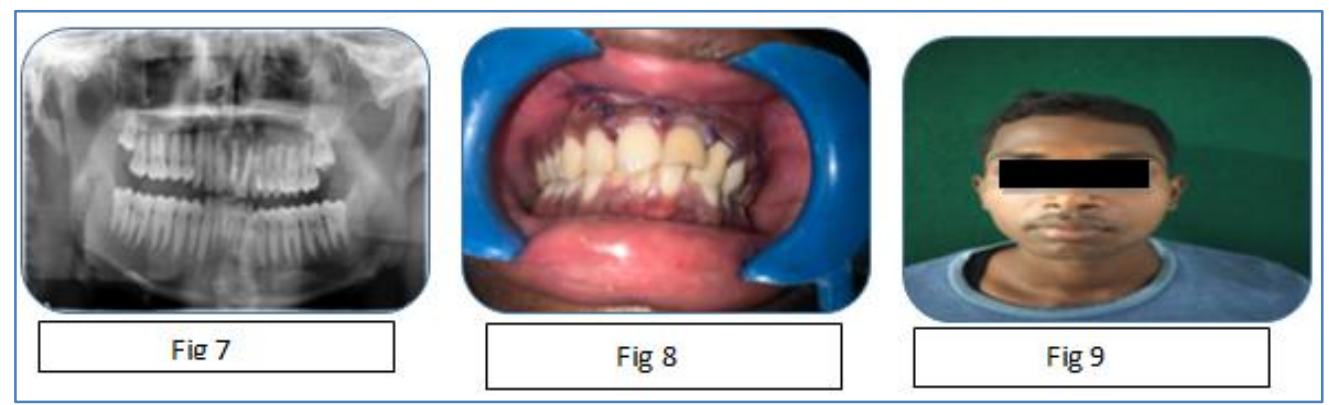

Fig-7-9: Postoperative photographs

\section{DISCUSSION}

A radicular cyst is most common inflammatory types and occur solely near the apices of the non-vital teeth as a reactive process, especially in the adults [1]. The prevalence is higher among the population in their third, second decade with more predilections for males $[2,3]$. They form as a result of the stimulation of the odontogenic epithelium in the vicinity of the root tip by necrotic pulp and of the root canal system.

In our case the cystic lesion filled the maxillary sinus and destroyed anterior wall of sinus. A similar case report was given by Mustafa et al. where the cyst filled the entire sinus [4]. Inflammatory cysts usually make of symmetrical expansion and spread into spaces sinus where the bone can be weakened easily. Several treatment modalities were available for the radical cyst. The choice of treatment may be determined by factors such as the lesion extension, relation with vital structures, origin, and clinical characteristics, and cooperation and patient's systemic condition that determine the choice of treatment.
In case of intraosseous lesions, needle aspiration is important to differentiate cystic lesions from solid lesions such as neoplasms. In our case, as cystic lesion was shown positive, decompression technique was performed. In the literature, different therapies are proposed, such as conservative root canal treatment without adjunctive therapy, decompression technique, and active nonsurgical decompression technique, aspiration through the root canal technique, marsupialization, apical resection, and surgical enucleation [5-7].

The traditional large cystic lesions of the jaws can be treated by total enucleation at a later stage with less invasive manner. However marsupilization is a time consuming treatment that can be only be performed in the complaint patient [8]. In the present case enucleation was preferred looking at the bone involvement and conserving the patient compliance. Periodic follow up was performed to assess the healing of the cystic cavity in view of the associated recurrent rate and no postoperative complications were encountered. 
Long-term observation is important to asses healing of periapical lesions. Shah et al. suggested recalling patients at intervals of 3 months, 6 months 1 year and 2 years [9].

\section{CONCLUSION}

In conclusion, enucleation of cyst with endodontic therapy and antrostomy is found to be effective for the treatment of large cysts involving maxillary sinus.

\section{REFERENCES}

1. Sevekar S, Subhadra HN, Das V. Radicular cyst associated with primary molar: surgical intervention and space management. Indian Journal of Dental Research. 2018 Nov 1;29(6):836.

2. Narula H, Ahuja B, Yeluri R, Baliga S, Munshi AK. Conservative non-surgical management of an infected radicular cyst. Contemporary clinical dentistry. 2011 Oct;2(4):368.

3. Kambalimath DH, Kambalimath HV, Agrawal SM, Singh M, Jain N, Anurag B, Michael P. Prevalence and distribution of odontogenic cyst in Indian population: a 10 year retrospective study. Journal of maxillofacial and oral surgery. 2014 Mar 1;13(1):10-5.

4. Nair PN, Sundqvist G, Sjögren U. Experimental evidence supports the abscess theory of development of radicular cysts. Oral Surgery, Oral Medicine, Oral Pathology, Oral Radiology, and Endodontology. 2008 Aug 1;106(2):294-303.
5. Sagit M, Guler S, Tasdemir A, Somdas MA. Large radicular cyst in the maxillary sinus. Journal of Craniofacial Surgery. 2011 Nov 1;22(6):e64-5.

6. Fernandes M, de Ataide I. Nonsurgical management of periapical lesions. J Conserv Dent. 2010;13:240-245

7. Sagit M, Guler S, Tasdemir A. Large radicular cyst in the maxillary sinus. J Craniofac Surg. 2011;22:e64-e65

8. Kocyigit ID, Atil F, Alp YE. Piezosurgery versus conventional surgery in radicular cyst enucleation. J Craniofac Surg. 2012;23:1805-1808

9. Kadam NS, De Ataide ID, Raghava P, Fernandes M, Hede R. Management of large radicular cyst by conservative surgical approach: a case report. Journal of clinical and diagnostic research: JCDR. 2014 Feb;8(2):239.

10. Shah N. Nonsurgical management of periapical lesions: A prospective study. Oral Surg Oral Med Oral Pathol. 1988; 66:365-7.

11. Shear M, Speight P. Cysts of the Oral and Maxillofacial Regions. Oxford: Wiley-Blackwell. 2007: 123

12. Samuels HS. Marsupialization: Effective management of large maxillary cysts. Oral Surg Oral Med Oral Pathol. 1965; 20:676-83.

13. Kumar JA, Achuthan N, Loganathan K, Augustine D. Effective management of a large radicular cyst with surgical enucleation. Oral Maxillofac Pathol J. 2014; 5:459-61. 